\title{
Serviço Social e pobreza
}

\author{
Social Work and Poverty
}

Este número da Revista Katálysis traz como eixo temático o Serviço Social e a pobreza. Trata-se de uma relação histórica, que, com diferentes conotações, acompanha o exercício profissional desde os anos de 1940 quando a profissão se institucionaliza na sociedade brasileira como um dos mecanismos acionados pelo Estado e pelo patronato, em sua intervenção reguladora frente à emergente questão social ${ }^{1}$ no país.

Efetivamente, a pobreza é parte da experiência diária do trabalho dos assistentes sociais. Convivemos muito de perto com a experiência trágica de pertencer às classes subalternizadas em nossa sociedade; conhecemos esse universo caracterizado por trajetórias de exploração, pobreza, opressão e resistência, observamos o crescimento da violência, da droga, e de outros códigos que sinalizam a condição subalterna: o desconforto da moradia precária e insalubre, as estratégias de sobrevivência frente ao desemprego, a debilidade da saúde, a ignorância, a fadiga, a resignação, a crença na felicidade das gerações futuras, o sofrimento expresso nas falas, nos silêncios, nas expressões corporais, nas linguagens além dos discursos.

Cada vez mais, é preciso considerar a impossibilidade de alcançar a realidade das classes subalternas sendo estranhos à sua cultura, à sua linguagem, a seu saber do mundo.

Do ponto de vista conceitual, é fundamental não perder de vista que a pobreza é expressão direta das relações vigentes na sociedade, relações extremamente desiguais, em que convivem acumulação e miséria. A pobreza brasileira é produto dessas relações que, em nossa sociedade, a produzem e reproduzem, quer no plano socioeconômico, quer nos planos político e cultural, constituindo múltiplos mecanismos que "fixam", os pobres em seu lugar na sociedade.

Abordar aqueles que socialmente são constituídos como pobres é penetrar num universo de dimensões insuspeitadas, marcado pela subalternidade, pela revolta silenciosa, pela humilhação e alienação e sobretudo, pela resiliência aliada às estratégias para melhor sobreviver, apesar de tudo.
Sabemos que novos fios estão tecendo novas sociabilidades que precisam ser desvendadas, mas, permanecem atuais os profundos e vastos sofrimentos gerados por uma ordem societária assentada na exploração de poucos sobre muitos, como observamos cotidianamente no exercício de nossa profissão.

Não podemos esquecer que as condições materiais da existência e as formas concretas que elas assumem nas vivências da sociabilidade, levam muitas vezes ao caminho da desesperança, do ilícito e de experiências conjugadas em outro jogo de referências tecido entre a dureza do desemprego e do trabalho incerto, a atração encantatória do moderno mercado de consumo, mas também os novos circuitos de sociabilidade e trabalho tramados na interface das mudanças operantes no mundo do trabalho e na cidade, e seus espaços (TELLES, 2007²). Trata-se, segundo a autora, de um jogo que se caracteriza pela erosão dos mundos sociais construídos em torno do trabalho regulado, que atinge duramente os que foram afetados pela reestruturação produtiva e os que, na "virada dos tempos", transitam nas suas dobras e constroem outros campos de possibilidades.

Embora a renda se configure como elemento essencial para a identificação da pobreza, o acesso a bens, recursos e serviços sociais ao lado de outros meios complementares de sobrevivência precisa ser considerado para definir situações de pobreza. É importante considerar que pobreza é uma categoria multidimensional, e, portanto, não se expressa apenas pela carência de bens materiais, mas é categoria política que se traduz pela carência de direitos, de oportunidades, de informações, de possibilidades e de esperanças, como anuncia José de Souza Martins ${ }^{3}$.

Submersos numa ordem social que os desqualifica, marcados por clichês: "inadaptados", "marginais", "problematizados", portadores de altos riscos e vulnerabilidades, os pobres representam a herança histórica da estruturação econômica, política e social da sociedade brasileira. Fazem parte dessa história, a tradição oligárquica e autoritária de uma sociedade de extremas desigualdades e assimetrias, caracteri- 
zada por sempre insuficientes recursos e serviços voltados para atender às necessidades dos segmentos das classes subalternas.

Quanto mais os assistentes sociais forem capazes de explicar e compreender as lógicas que produzem a pobreza e a desigualdade, constitutivas do capitalismo, mais condições terão para intervir, para elaborar respostas profissionais qualificadas do ponto de vista teórico, político, ético e técnico (o conhecimento teórico é a primeira ferramenta do trabalho do assistente social). Mas, se fundamental é decifrar as lógicas do capital, sua expansão predatória e sem limites, desafiante é, também, saber construir mediações para enfrentar as questões que se colocam no tempo miúdo do dia a dia da profissão. É nesse tempo que podemos partejar o novo, construir resistências, construir hegemonia, enfrentar as sombras que mergulham esta imensa parcela de humanidade explorada, enganada, iludida, massacrada, gente que fica à espera em longas filas para receber os "benefícios" que os assistentes sociais operacionalizam.

Construir mediações é um desafio porque supõe um movimento de passagem de nossas concepções ontológicas, de nossos fundamentos teóricometodológicos para esse tempo miúdo, para situações concretas. Essas mediações são teóricas, técnicas e políticas. Por exemplo: a estruturação de um serviço, a construção de um programa, a organização de um CRAS, de um trabalho socioeducativo, e outros.

Do que estou tratando? Estou tratando de situações cotidianas onde as desfigurações resultantes da espoliação deixam seus impactos. Estou tratando de situações que são alvo - objeto de políticas que nós operacionalizamos. Estou tratando da questão de construção de hegemonia, no exercício concreto de uma profissão. Estou afirmando o processo de construção de direitos não apenas como questão técnica, mas como questão essencialmente política, lugar de contradições e resistência. Âmbito a partir do qual seja possível "modificar lugares de poder demarcados tradicionalmente e, portanto, de abertura para construir outros" e não apenas realizar gestões bem sucedidas de necessidades sociais. Estou colocando em questão a luta por direitos como uma questão a ser politizada, como estratégia capaz de romper, ou iniciar a ruptura, do círculo fechado da dominação. Estou colocando a reivindicação dos direitos sociais como parte da luta de classes.

Sabemos que permanecem na Política Social brasileira, âmbito privilegiado de nossa inserção profissional, concepções e práticas assistencialistas, clientelistas, primeiro damistas e patrimonialistas. Observamos na rede solidária a expansão de serviços a partir do dever moral, da benemerência e da filantropia (que em si mesmos, não realizam direitos). Ainda encontramos em nosso trabalho uma cultura moralista e autoritária que culpa o pobre por sua pobreza.
É inserido neste contexto, desafiado pelas mudanças em andamento, convivendo cotidianamente com a violência da radicalização da exploração e da expropriação das classes subalternizadas em nossa sociedade e com as incontáveis faces da exclusão social, que o assistente social brasileiro trava o embate a que se propõe: o de avançar em seu projeto ético-político na direção de uma sociabilidade mais justa, mais igualitária e onde direitos sociais sejam observados.

Um projeto de profissão, como sabemos, envolve um conjunto de componentes que necessitam se articular: são valores, saberes e escolhas teóricas, práticas, ideológicas, políticas, éticas, normatizações acerca de direitos e deveres, recursos políticoorganizativos, processos de debate, investigações, em interlocução crítica com o movimento da sociedade na qual o Serviço Social é parte e expressão.

Não são poucos os desafios que interpelam a profissão quando fazemos aposta em outra ordem societária. Temos aí um papel de politizar e dar visibilidade aos interesses das classes subalternas e sabemos que não basta a alta qualidade técnica de nosso trabalho. Tarefa difícil construir uma nova cultura política na política social, âmbito privilegiado de nosso trabalho profissional. Estamos no olho do furacão... E, embora saibamos que escapa às políticas sociais, às suas capacidades, desenhos e objetivos reverter níveis tão elevados de desigualdade, como os encontrados no Brasil, não podemos duvidar das virtualidades possíveis dessas políticas. Elas podem ser possibilidade de construção de direitos e iniciativas de "contradesmanche" de uma ordem injusta e desigual.

Maria Carmelita Yazbek, setembro 2010.

\section{Notas}

1 Por questão social entendemos a disputa, pelas classes sociais, da riqueza socialmente construída na sociedade capitalista.

2 TELLES, V. da S. Transitando na linha de sombra, tecendo as tramas da cidade (anotações inconclusas de uma pesquisa). In: OLIVEIRA, F.; RIZEK, C. S. A era da indeterminação. São Paulo: Boitempo, 2007.

3 MARTINS, J.de S. Omassacre dos inocentes. Acriança sem infância no Brasil. São Paulo: Hucitec, 1991.

\author{
Maria Carmelita Yazbek \\ mcyaz@uol.com.br \\ Pós-Doutoramento no Inst. de Estudos Avançados \\ da Universidade de São Paulo (USP) \\ Doutorado em Serviço Social pela PUC-SP \\ Professora da Pós-Graduação em Serviço Social \\ da PUC-SP
}

